\title{
Egipto: Expansión del acceso a la atención postaborto
}

Frontiers in Reproductive Health

Follow this and additional works at: https://knowledgecommons.popcouncil.org/departments_sbsr-rh How does access to this work benefit you? Let us know!

\section{Recommended Citation}

"Egipto: Expansión del acceso a la atención postaborto," FRONTERAS Resúmenes de Investigación Operativa. Ciudad de México: Population Council, 2001. 
Egipto

Atención

postaborto

\section{Resumen de 108}

\section{Expansión del acceso a la atención postaborto}

\begin{abstract}
La capacitación de los proveedores y la introducción de un protocolo de manejo de casos produjeron mejoras en la atención postaborto que se ofrece en diez hospitales universitarios y públicos en Egipto. Las pacientes dijeron haber esperado menos tiempo para ser atendidas y estar más satisfechas con los servicios médicos proporcionados. Los médicos adoptaron tratamientos asociados a menos complicaciones y dieron más información relacionada con la salud a sus pacientes.
\end{abstract}

\section{Antecedentes}

Un estudio piloto realizado en 1994 en dos hospitales egipcios mostró que al mejorar la atención postaborto (APA) y capacitar a los médicos en aspiración manual endouterina (AMEU), control de infecciones y consejería, se producían mejoras significativas en la atención de las pacientes postaborto. En 1997, la Sociedad Egipcia para la Atención de la Fecundidad, con el apoyo del Population Council, realizó un estudio cuyo objetivo fue institucionalizar la atención médica postaborto mejorada y las prácticas de consejería en diez hospitales (siete de gobierno y tres universitarios).

Como parte de este estudio, cinco médicos de cada hospital asistieron a un curso de capacitación en AMEU, control de infecciones y consejería en planificación familiar (PF), de cinco días de duración. Posteriormente, los médicos supervisaron durante cuatro meses un programa de capacitación en servicio para médicos y enfermeras en los diez hospitales. Asimismo, se introdujo un protocolo de manejo de casos, que incluía tratamiento médico de urgencia, control del dolor y consejería en PF. Los investigadores midieron los cambios en conocimientos y prácticas al aplicar encuestas antes (a 255 médicos, 311 enfermeras y 508 pacientes) y después (a 246 médicos, 263 enfermeras y 497 pacientes) de la intervención. También se recopilaron datos de 1036 registros médicos.

\section{Resultados}

Los médicos capacitados ampliaron significativamente sus conocimientos sobre complicaciones a corto plazo, impactos adversos en la salud y el retorno inmediato de la fecundidad después del tratamiento postaborto. Se observó que después de la intervención, era más probable que los médicos aceptaran que las pacientes APA debían recibir información sobre la causa del aborto, la importancia de comer bien, descansar y usar algún método anticonceptivo durante su recuperación.

Atención a Pacientes Postaborto

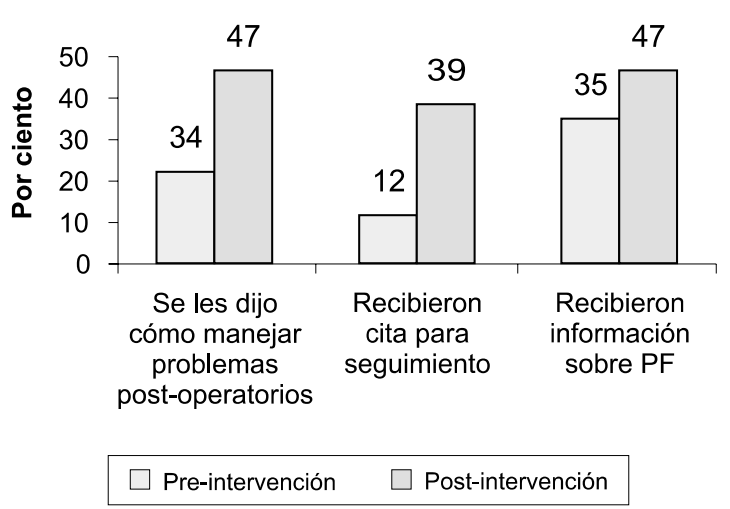


Después de la intervención, los médicos utilizaron la AMEU en el 57 por ciento de los casos que requerían tratamiento médico de urgencia, abandonando así la práctica casi universal del legrado uterino instrumental (LUI). Más de tres de cada cuatro médicos informaron que, comparado con el LUI, el uso de la AMEU redujo las complicaciones derivadas del procedimiento. Más de la mitad de los médicos dijeron que dicha técnica es más efectiva y fácil de usar que la de LUI.

La adopción de la AMEU también ocasionó que se cambiara del uso de la anestesia general a la anestesia local en cerca del 30 por ciento de los casos. Después de la intervención, aumentó significativamente la proporción de médicos que declaraban que la sedación ligera y la anestesia local pueden reducir la ansiedad de las pacientes. Sin embargo, las técnicas para controlar el dolor todavía se deben mejorar: el 18 por ciento de las pacientes postintervención no recibieron ningún medicamento para el dolor. Aunque el número de pacientes que dijo haber experimentado dolor extremo no aumentó significativamente, el número de informes de dolor moderado se quintuplicó (del 5 al 27 por ciento).

Después de la intervención, casi tres de cada cuatro pacientes $(73 \%)$ dijeron que el servicio que habían recibido en el hospital había sido excelente, comparado con el 44 por ciento antes de la intervención. Después de la intervención, una mayor proporción de pacientes informó que los prestadores habían sido cordiales, haber esperado menos de 30 minutos para ser atendidas y haber recibido información sobre posibles complicaciones, cómo manejarlas y cómo darles seguimiento.
La proporción de pacientes que dijo haber recibido información sobre planificación familiar en el hospital aumentó del 35 al 47 por ciento. Sin embargo, únicamente el siete por ciento de las pacientes recibió un método anticonceptivo antes del alta hospitalaria.

\section{Implicaciones normativas}

Se deben estandarizar la capacitación y los protocolos de la APA, incluyendo los procedimientos para controlar el dolor y las infecciones, en los hospitales y las escuelas de medicina. Los hospitales universitarios y públicos deben considerar los suministros para la AMEU en sus presupuestos, y asegurar la existencia de medicamentos para el dolor.

Todavía es necesario mejorar algunos aspectos de la APA: el manejo del dolor, la información proporcionada a las pacientes y la prestación de servicios de consejería y de PF. Las enfermeras deben participar activamente en las actividades dirigidas a consolar, aconsejar e informar a las pacientes. También deben desarrollarse guías sencillas sobre instrumentos de AMEU y consejería en PF.

\section{Utilización}

Como parte del proyecto "Madre Saludable/Hijo Saludable" del Ministerio de Salud y Población, se está capacitando a los proveedores en AMEU y en otros elementos de APA, entre ellos, el control del dolor y la vinculación con los servicios de planificación familiar. Diez nuevos hospitales han introducido la atención postaborto mejorada a través de dicho proyecto: cinco en Aswan, dos en Luxor y tres en Qena del Sur. Ya se iniciaron actividades para incluir otros sitios en Fayoum y Bani Sewef.

Marzo 2001

Nawar, Laila et al., 1997. Scaling-up Improved Postabortion Care in Egypt: Introduction to University and Ministry of Health and Population Hospitals. Para obtener más información o el informe en inglés de este proyecto, escriba o llame a: Population Council, 6A Mohamed Bahie Eddine Bakarat St., $10^{\text {th }}$ floor, Giza, Egipto. Tel. 20-2-571-9252; Fax 20-2-570-1804; E-mail: frontiers@pccairo.org.

Este proyecto fue posible gracias al apoyo de la Agencia de los Estados Unidos para el Desarrollo Internacional (USAID) bajo los contratos números C-00-90-002-01 Y DPE-3030-8-00-0023-00. 